\title{
Pharmacognostic Specification and Rotenone Content in Derris elliptica Stems
}

\author{
Krittapat Phairoh ${ }^{1}$, Parichart Hongsing ${ }^{2}$, Chanida Palanuvej' and Nijsiri Ruangrungsi ${ }^{1,3, *}$
}

\section{Krittapat Phairoh' ${ }^{1}$, Parichart Hongsing ${ }^{2}$, Chanida Palanuvej' and Nijsiri Ruangrungsi ${ }^{1,3, *}$}

'Public Health Sciences Program, College of Public Health Sciences, Chulalongkorn University, Bangkok, 10330, THAILAND. ${ }^{2} S c h o o l$ of Integrative Medicine, Mae Fah Luang University, Chiangrai, 57100, THAILAND.

${ }^{3}$ College of Pharmacy, Rangsit University, Pathumthani, 12000, THAILAND.

\section{Correspondence}

\section{Nijsiri Ruangrungsi}

Public Health Sciences Program, College of Public Health Sciences, Chulalongkorn University, Bangkok, 10330; College of Pharmacy, Rangsit University, Pathumthani, 12000, THAILAND.

\section{E-mail: Nijsiri.r@chula.ac.th}

History

- Submission Date: 19-08-2020;

- Review completed: 22-09-2020;

- Accepted Date: 01-10-2020.

\section{DOI : 10.5530/pj.2021.13.17}

Article Available online http://www.phcogj.com/v13/i1

\section{Copyright}

(c) 2021 Phcogj.Com. This is an openaccess article distributed under the terms of the Creative Commons Attribution 4.0 International license.

\begin{abstract}
Introduction: Derris elliptica (Wall.) Benth. (Leguminosae) is the tropical plant which has been used as natural poison as well as veterinary medicine due to its best-known phytochemical compound, rotenone to kill invertebrates and fish. However, there is no report on pharmacognostic specification and quantification of rotenone content from $D$. elliptica stems. Objective: This present study aimed to conduct the pharmacognostic parameters as well as to conduct the validated methods to quantify rotenone content in D. elliptica stems following WHO guideline. Methods: Dried D. elliptica stems from 15 different areas in Thailand were examined for pharmacognostic secification. Their rotenone contents were quantitatively analyzed by TLC densitometry using winCATS software as well as TLC-image analysis using ImageJ free software. Results: Macroscopic and microscopic characteristics, TLC fingerprint and physicochemical parameters were reported in this study. The water content, loss on drying, total ash content and acidinsoluble ash content were determined to be $8.81 \pm 1.30,5.77 \pm 0.92,7.35 \pm 0.63,1.221 \pm 0.20 \%$, respectively. The ethanol, and water-soluble extractive values were found to be $4.07 \pm 1.23$ and $11.31 \pm 1.68 \%$, respectively. Additionally, the validation method for quantification of rotenone content was developed. The contents of rotenone in D. elliptica stem ethanolic extract evaluated by TLC-densitometry and TLC-image analysis were found to be $0.2870 \pm 0.1242$ and $0.2844 \pm 0.1209 \%$ by dried weight, respectively. The result between these two analytical methods were shown no significant difference. Conclusion: The validated methods were able to effectively quantify rotenone content in D. elliptica stems from various locations in Thailand which could be used for the specification of this raw material with reference to its chemical marker. Thus, this study provides the necessary and adequate information for authentication and standardization of $D$. elliptica stems.

Key Words: TLC-densitometry, TLC-image analysis, Quality evaluation.
\end{abstract}

\section{INTRODUCTION}

D. elliptica (Wall.) Benth. is the evergreen shrub and climbing plant with the woody stem in Leguminosae family. This East Asian plant is called "Lotin or Hang Lai Daeng" in Thai and is world-famous for being used as organic piscicide, acaricide and insecticide in veterinary medicine. ${ }^{1}$ Rotenone (also known as nicouline, dactinol or tubatoxin) is an isoflavonoid primarily found in Leguminosae family, especially in Derris plants (Figure 1). The toxicity of rotenone was classified as a medium hazardous class II pesticide by World Health Organization (WHO), indicating $\mathrm{LD}_{50}$ at the range of $132-1500 \mathrm{mg} / \mathrm{kg}$. ${ }^{2}$ Since this botanical compound has been used widely as the fish killer, the United States Environmental Protection Agency (USEPA) also reported the very low bioaccumulation of rotenone-treated fish, for example, consuming approximately 274,000 rotenone-treated fish would develop acute toxicity in human. ${ }^{3}$ Thus, it is claimed to be safe compound for human with properly use. On the other hands, its neurotoxicity has been evaluated as the potential substance to induce Parkinsonism in animal models which are beneficial to evaluate numerous compounds to treat Parkinson's disease. ${ }^{4,5}$

Currently, WHO established the protocols to standardize the herbal plants which are the important source of beneficial compounds. Such processes include macroscopic, microscopic and physicochemical evaluations are required in the

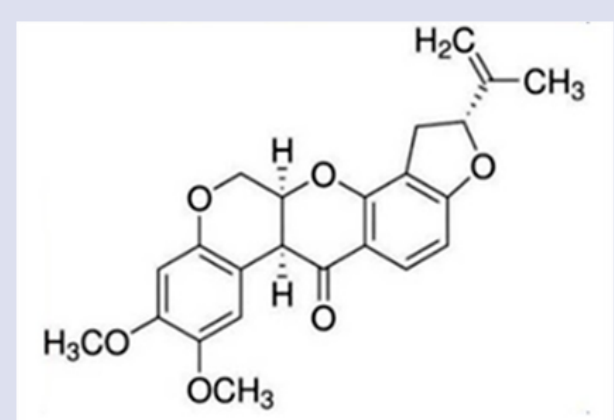

Figure 1: Chemical structure of rotenone.

manners of identification and quality control of the plants. ${ }^{6}$ Moreover, the European Medicine Agency (EMEA) defines the constituents in the plant as the chemical marker which can be used in order to indicate the quality of the beneficial compounds in the plants as well as in the botanical products. ${ }^{7}$ Taken together, the aforementioned parameters from $\mathrm{WHO}$ and EMEA are essential for quality control of herbal plants.

Despite the usefulness of rotenone in D. elliptica stems, there is no reports on its pharmacognostic parameters as well as the simple method to quantify rotenone content in D. elliptica stems. Thin layer chromatography (TLC) is one of the practical procedures for both quantitative and qualitative analyses to identify and isolate active compounds in the medicinal plants due to its rapidness, easiness and

Cite this article: Phairoh $K$, Hongsing $P$, Palanuvej $C$, Ruangrungsi N. Pharmacognostic Specification and Rotenone Content in Derris elliptica Stems. Pharmacog J. 2021;13(1): 12432. 
inexpensiveness. ${ }^{8,9}$ Therefore, this study aimed to develop and validate the techniques to quantify rotenone content using TLC-densitometry and TLC-image analysis as well as to evaluate the pharmacognostic parameters for identification of D. elliptica stems collected throughout different locations in Thailand.

\section{MATERIALS AND METHODS}

\section{Plant Materials}

D. elliptica stems were collected from 15 sources throughout Thailand. All sample were authenticated by Assoc. Prof. Dr. Nijsiri Ruangrungsi. The voucher specimens were deposited at the College of Public Health Sciences, Chulalongkorn University, Thailand. After the removal of foreign matters, each authentic sample was air-dried and pulverized into powders.

\section{Plant extraction}

Five grams of D. ellitica powder were exhaustively extracted with $95 \%$ ethanol by Soxhlet apparatus, filtered and evaporated to dryness. The extract was dissolved with ethanol to get the concentration of $50 \mathrm{mg} /$ $\mathrm{ml}$. This extract was stored in refrigerator at $4{ }^{\circ} \mathrm{C}$ and further used for TLC densitometry and TLC image analysis.

\section{Preparation of standard solution of rotenone}

One milligram of standard rotenone was dissolved in $1 \mathrm{ml}$ of ethanol. The stock solution was diluted to obtain the series of standard solution range from 0.2 to $1 \mathrm{mg} / \mathrm{ml}$.

\section{Determination of pharmacognostic specification}

According to the World Health Organization, the pharmacognostic parameters conducted in the study were macroscopic and microscopic examinations, determinations of loss on drying, total ash, acidinsoluble ash, water content, solvent extractive values, as well as TLC fingerprinting. ${ }^{6}$ For macroscopic examination, D. ellitica aerial part and stem were observed for their morphological characteristics. For microscopic examination, the transversely-cut $D$. ellitica stem and $D$. ellitica powder were demonstrated under microscope (the objective lens with magnification of 10X, 20X, or $40 \mathrm{X}$, and the eyepiece lens with magnification of 10X) for their histological characteristics and illustrated by hand proportionally. Regarding the determination of loss on drying, $3 \mathrm{~g}$ of ground sample was dried at $105^{\circ} \mathrm{C}$ for $6 \mathrm{~h}$ until constant weight. To determine the total ash, $3 \mathrm{~g}$ of ground sample was incinerated at $500{ }^{\circ} \mathrm{C}$ for $5 \mathrm{~h}$ to obtain white-grayish ash. The obtained ash was boiled with $25 \mathrm{ml}$ of $\mathrm{HCl}(70 \mathrm{~g} / \mathrm{l})$ to get the insoluble matter that was then incinerated at $500{ }^{\circ} \mathrm{C}$ for $5 \mathrm{~h}$ to obtain the acid-insoluble ash. To determine the water content, $50 \mathrm{~g}$ of the ground sample was distilled with water-saturated toluene using azeotropic distillation. For the determination of solvent extractive values, $5 \mathrm{~g}$ of the ground sample was extracted with $70 \mathrm{ml}$ of $95 \%$ ethanol or water by maceration with shaking for $6 \mathrm{~h}$, allowed to stand still for $18 \mathrm{~h}$ then filtered. The marc was washed and the filtrate was adjusted to $100 \mathrm{ml}$ with ethanol or water, and $20 \mathrm{ml}$ of the filtrate was evaporated to dryness and then dried in oven at $105^{\circ} \mathrm{C}$ for 6 hours to determine the solvent extractive values. All samples were performed in triplicate and calculated in percentage of dry weight of crude drug. The results were displayed as grand mean \pm pooled standard deviation. To demonstrate the TLC fingerprinting, the ethanolic extract of $D$. elliptica was examined using silica gel $60 \mathrm{GF}_{254}$ TLC plate as stationary phase and a mixture of toluene: chloroform: acetone: formic acid (5: 4: 1: 0.2) as mobile phase. The plate was detected under ultraviolet (UV) light $(254,365 \mathrm{~nm})$, and observed under daylight with TLC visualization reagent $\left(10 \% \mathrm{H}_{2} \mathrm{SO}_{4}\right.$ in methanol).

\section{Quantitative analysis of rotenone by TLC densitometry}

Three microliters of D. ellitica stem ethanolic extract (from 15 different sources) and standard solutions of rotenone were applied onto the silica gel $60 \mathrm{GF}_{254}$ TLC plate. The plate was developed in a solvent system of toluene: chloroform: acetone: formic acid (5: 4: 1: 0.2). After that, the plate was scanned with CAMAG TLC Scanner 4 (CAMAG, Switzerland) under the wavelength of $301 \mathrm{~nm}$. The rotenone content was calculated from the peak area of each chromatographic band against the standard calibration curve using winCATS software (Camag, Switzerland).

\section{Quantitative analysis of rotenone by TLC image analysis}

Rotenone spots on the developed TLC plate were photographed under short UV light $(254 \mathrm{~nm}$ ) by a digital camera attached to the UV cabinet (Spectroline, USA). Peak area of each spot was quantitated using ImageJ free software which developed from Department of Health and Human Services, National Institutes of Health (NIH) in the United State. ${ }^{10}$ The content of rotenone was determined by comparing peak area to the standard calibration curve obtained from the same TLC plate.

\section{Method validation}

This part was investigated by following ICH guideline. ${ }^{11}$ LOD and LOQ were estimated based on the residual standard deviation of a regression line $(\sigma)$ and the slope $(S)$ with the equation of: $3.3 S \sigma / S$ and $10 \sigma / S$ respectively. Accuracy was carried out as the percentage recovery of the sample spiked with the known amounts of standard. The precision was performed using 3 concentrations ( 3 replicate each) in the same day (repeatability) and other 3 different days (intermediate precision) and were expressed as the percentage of relative standard deviation (RSD). Specificity was evaluated according to the similarity of the absorbance spectra at the peak apex among all samples and standard rotenone as well as the similarity of the absorbance spectra at up-slope, apex, and down-slope of the peak. The robustness was performed by varying the ratio of the solvent system and expressed as \% RSD of peak area.

\section{Data analysis}

Grand mean \pm pooled standard deviation was used for the analysis of physicochemical parameters. Rotenone content was evaluated according to the percent yield. The results obtained from TLC-densitometry and TLC image analysis were statistically compared by paired student $t$-test $(\mathrm{P} \leq 0.05)$.

\section{RESULTS AND DISCUSSION}

\section{Pharmacognostic specification}

Macroscopic and microscopic examinations are preliminary techniques for plant material identification. The dried stem of crude drug was light yellow with dark grayish-brown bark (Figure 2). The macroscopic and microscopic characteristics of D. elliptica were illustrated by hand drawing (Figure 3). The illustrated characteristics were considered to be the simplest and the most inexpensive tools to identify this crude drug. The histological characteristics of D. elliptica stem powder included fragments of spiral vessels, sclereids, groups of fibers, bordered pitted, starch granules, prisms (Figure 4). The transverse section of D. elliptica dried stem revealed the anatomical characteristics including epidermis, cork cambium, parenchyma, vascular cambium, xylem vessel, phloem vascular bundle and pith (Figure 5).

The results of physicochemical parameters of D. elliptica stems were shown in Table 1 . The loss on drying, total ash, acid-insoluble ash, water content, ethanol, and water-soluble extractive values were found to be $5.77 \pm 0.92,7.35 \pm 0.63,1.22 \pm 0.20,8.81 \pm 1.30,4.07 \pm 1.23$ and 11.31 $\pm 1.68 \mathrm{~g} / 100 \mathrm{~g}$ of dry weight, respectively. The total ash $(7.35 \pm 0.63$ $\mathrm{g}$ of dry weight) represented inorganic substances in the crude drugs, 

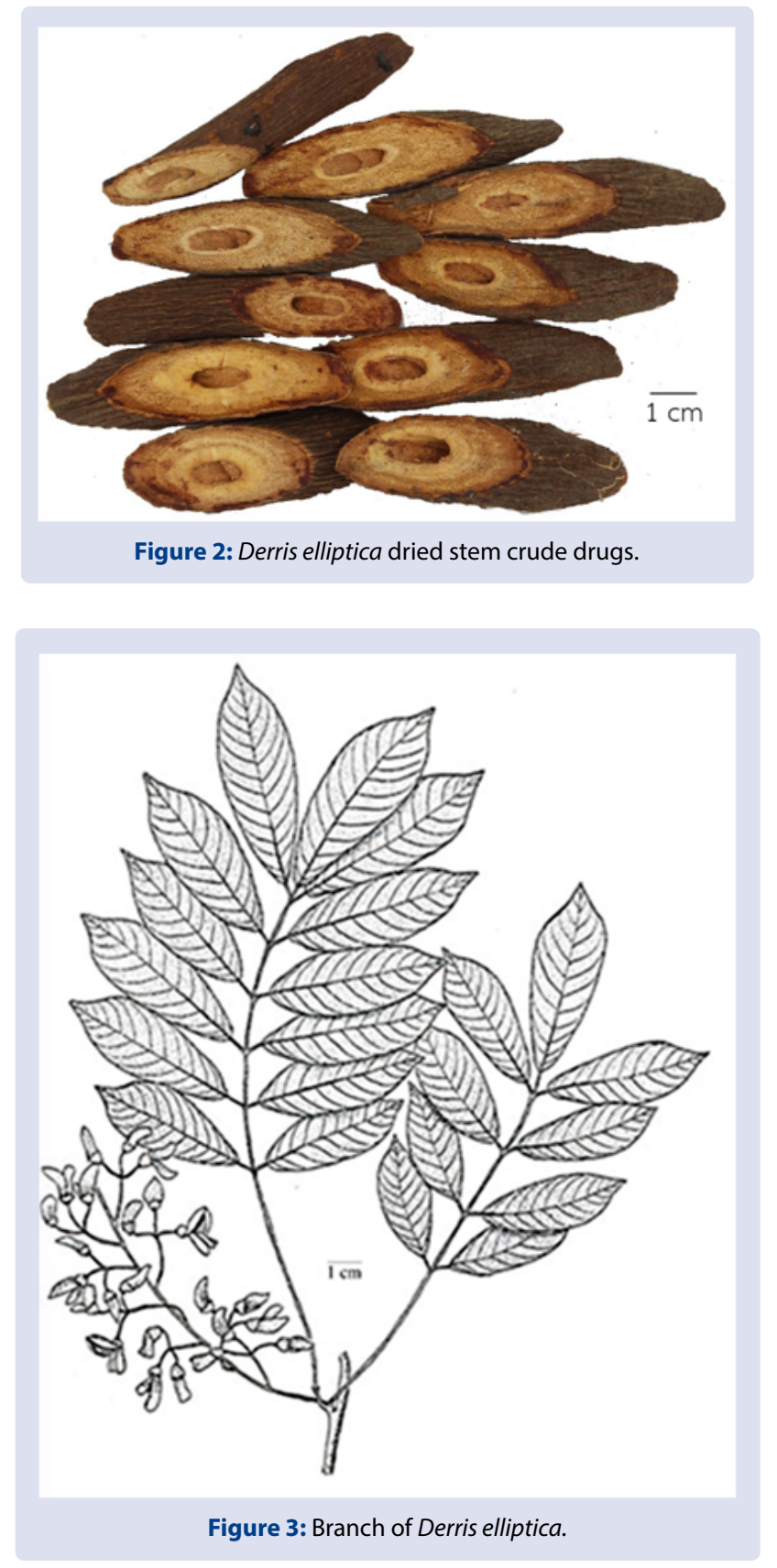

Table 1: Physiochemical characteristics of $D$. elliptica dried stems.

\begin{tabular}{ccc}
\hline Parameter & \multicolumn{2}{c}{ Content $(\mathbf{g} / 100 \mathrm{~g})$} \\
\cline { 2 - 3 } & Mean \pm SD $^{*}$ & Min - Max \\
\hline Acid-insoluble ash & $1.22 \pm 0.20$ & $0.92-1.67$ \\
Total ash & $7.35 \pm 0.63$ & $6.06-8.44$ \\
Ethanol-soluble extractive matter & $4.07 \pm 1.23$ & $1.34-6.06$ \\
Water-soluble extractive matter & $11.31 \pm 1.68$ & $8.46-13.73$ \\
Loss on drying & $5.77 \pm 0.92$ & $4.15-7.50$ \\
Water content & $8.81 \pm 1.30$ & $7.22-11.89$ \\
\hline
\end{tabular}

"The parameters were shown as grand mean \pm pooled SD. Samples were collected from 15 sources in Thailand. Each sample was tested in triplicate. 

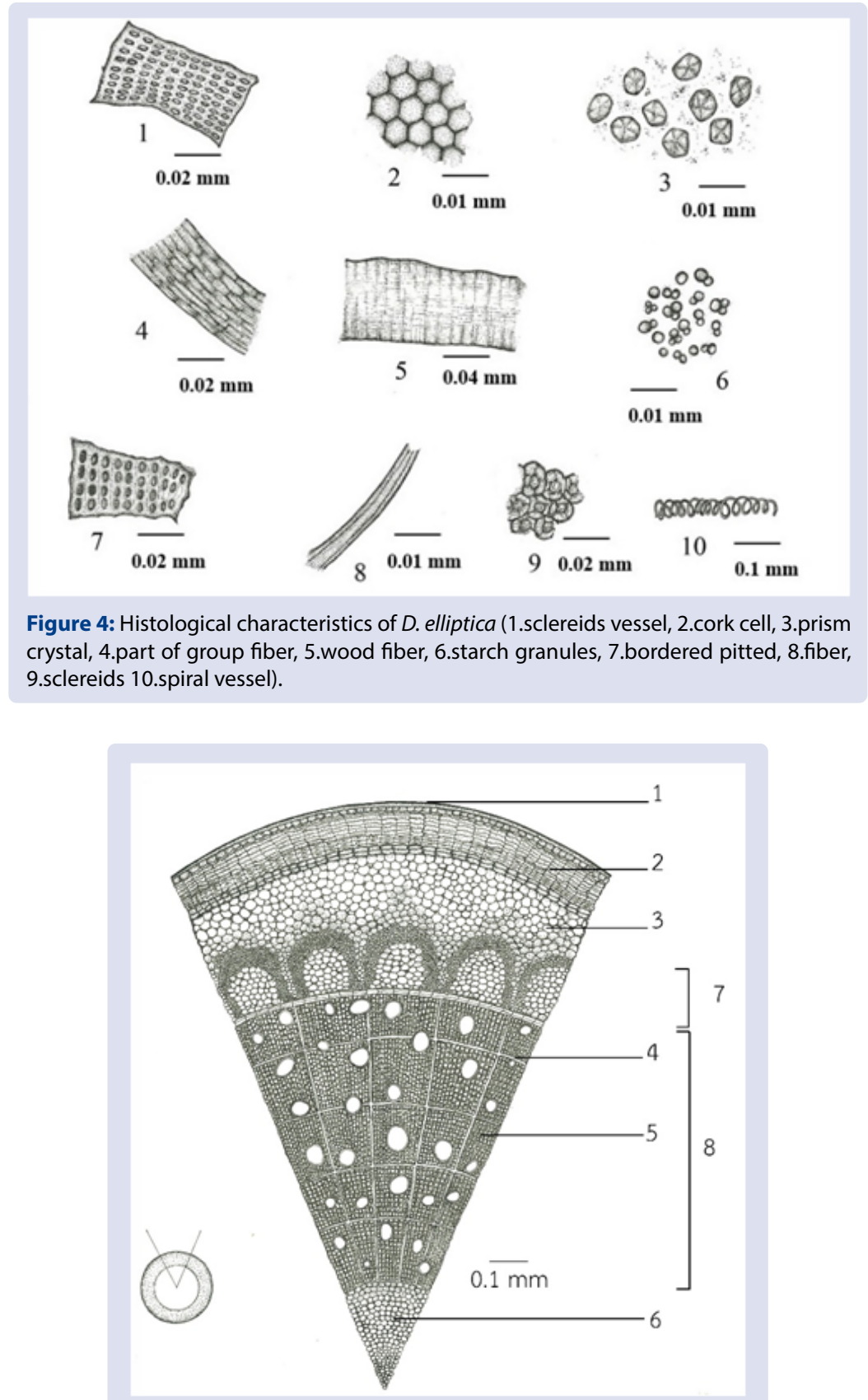

Figure 5: The transverse section of $D$. elliptica dried stem (1.epidermis, 2.cork cambium, 3.parenchyma, 4. xylem vessel, 5. xylem ray 6. pith, 7. vascular cambium, 8. vascular bundle).

such as calcium, sodium, potassium, etc. The acid-insoluble ash (1.22 \pm $0.20 \mathrm{~g}$ of dry weight) was mostly aluminum and silicon. The ash values can be used to specify the purity of the crude drugs by determining adulteration, contamination or substitution of plant materials.

Loss on drying and water content define water present in the crude drugs. Excessive amount of water in herbal plant materials which might be due to the surrounding humidity during storage can promote the growth of bacteria or fungi, causing the degradation. Therefore, the values of loss on drying and water content could be used as indicators to discourage the microbial growth.

The quality control is required to determine the phytochemical constituents in herbal plants to ensure the stability of natural products obtained from plant sources. ${ }^{12}$ Chemical compounds extracted from particular solvents can be estimated from the extractive values. Nonetheless, the amounts of active compounds present in herbal plant materials can be varied, due to the extraction methodology. To extract Thai medicinal plants, extraction using alcohol or water as a solvent is commonly used. The water-soluble extractive value $(11.31 \pm 1.68$ $\mathrm{g} / 100 \mathrm{~g}$ of dry weight) that was higher than ethanol-extractive value $(4.07 \pm 1.23 \mathrm{~g} / 100 \mathrm{~g}$ of dry weight) indicated that D. elliptica stems contained great amount of polar active compounds. Apart from that, the phytochemical fingerprinting is considered to be a reliable tool in primary identifying the herbal materials. TLC fingerprinting (Figure 6) displayed the characteristics of active compounds found in D. elliptica stems, which could be used as a reference for further plant identification. 


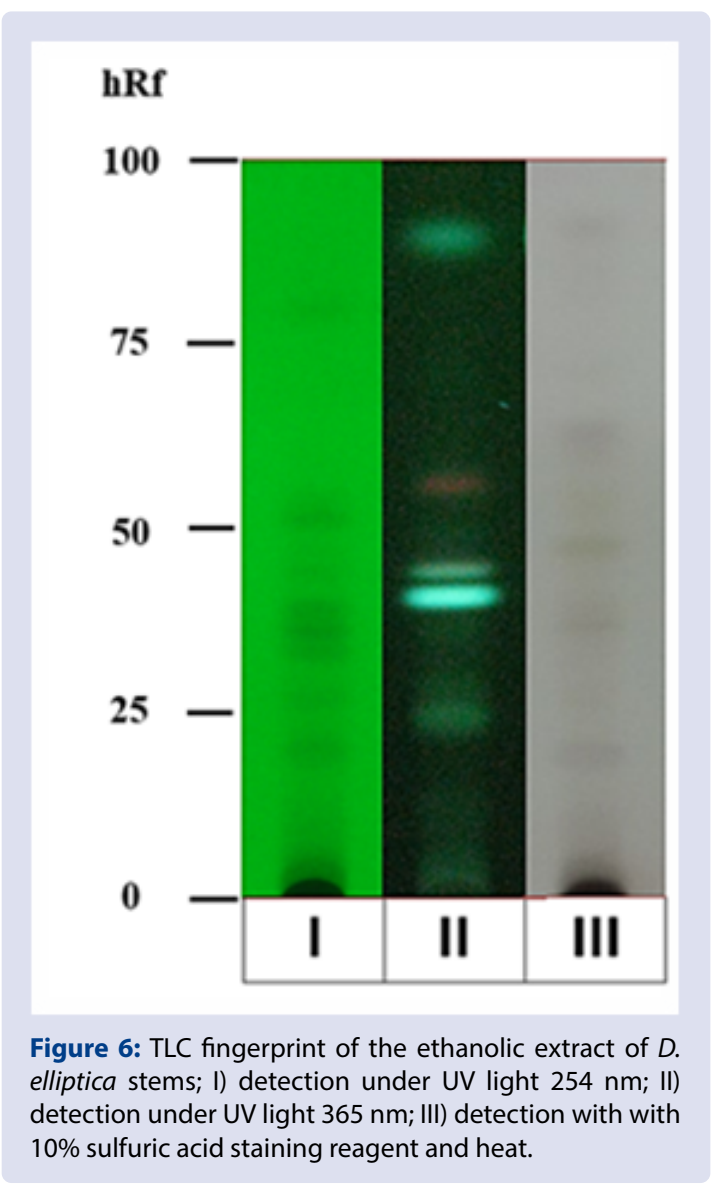

Table 2: Rotenone content (g/100g) in D. elliptica from 15 sources throughout Thailand (each source was done in triplicate).

\begin{tabular}{ccc}
\hline \multirow{2}{*}{ Source } & \multicolumn{2}{c}{ Rotenone content $(\mathbf{g} / \mathbf{1 0 0 g})$} \\
\cline { 2 - 3 } 2 & TLC-densitometry method & TLC-image analysis \\
\hline 2 & 0.0992 & 0.1035 \\
4 & 0.1784 & 0.1773 \\
5 & 0.1903 & 0.1945 \\
6 & 0.1428 & 0.1812 \\
7 & 0.3440 & 0.1448 \\
8 & 0.2157 & 0.3308 \\
9 & 0.1756 & 0.2127 \\
10 & 0.3224 & 0.1814 \\
11 & 0.4582 & 0.3245 \\
12 & 0.4710 & 0.4506 \\
13 & 0.3710 & 0.4777 \\
14 & 0.4410 & 0.3695 \\
15 & 0.3994 & 0.4279 \\
Mean \pm SD & 0.3084 & 0.3808 \\
& $0.2870 \pm 0.1242$ & 0.3080 \\
\hline
\end{tabular}

Quantitative analysis of rotenone content in D. elliptica stems

The content of active compounds in herbal plants can be varied due to geographical areas, harvesting seasons, drying processes or extraction procedures. Therefore, the quantitation of the active constituents can indicate the quality of the plant materials. ${ }^{7}$ In the present study, the thin layer chromatographic (TLC) technique was developed because of its rapidness and easiness. ${ }^{13}$ Based on the findings, the percent yield of ethanolic extracts of $D$. elliptica stems was $13.93 \pm 2.82 \mathrm{~g} / 100 \mathrm{~g}$ by dry weight. The rotenone content in D. elliptica stem ethanolic extract was determined using TLC-densitometry and TLC-image analysis, with the solvent system of toluene: chloroform: acetone: formic acid (5: 4: 1: 0.2 ). The results were found to be $0.29 \pm 0.12$ and $0.28 \pm 0.12 \mathrm{~g} / 100$ of dry stems for TLC-densitometry and TLC-image analysis, respectively. TLC chromatogram under UV $254 \mathrm{~nm}$ is shown in Figure 7, and TLC densitogram scanned in the range of $200-700 \mathrm{~nm}$ is shown in Figure 8. Densitometry is the measurement of a reflection in absorbance or fluorescence mode with the maximal wavelength, both quantitatively and qualitatively, the amount of chemical constituents determined 
by TLC-densitometry analysis is highly reliable. ${ }^{14}$ Alternatively, TLC-image analysis can be used for cost-effective purpose as ImageJ software, developed by the National Institutes of Health, provides free access for all users. ImageJ is able to detect the pixel intensity in the image of TLC spots taken by digital camera, and then transform that intensity to chromatographic peaks. ${ }^{8}$ Statistically using paired $t$-test, the rotenone content obtained from both methods was not significantly different $(P>0.05)$. The results highlighted that TLC image analysis was affordable and simple that it could be used as an alternative method to measure the rotenone contents in D. elliptica stems.

The optimized TLC-densitometry and TLC-image analysis were validated for the determination of rotenone content in D. elliptica stem extracts. The specificity was established by comparing UV spectrum of the peak among standard rotenone with all samples at three positions of the peak (apex, upslope, and down-slope). The maximum wavelength $\left(\lambda_{\max }\right)$ of rotenone was at $301 \mathrm{~nm}$. The validity of TLC-densitometry and TLC image analysis were displayed in Table 3.
The polynomial calibration curves ranged from 0.9 to $6.0 \mu \mathrm{g} / \mathrm{spot}$ (Figure 9). The values of accuracy represented by \% recovery of both methods were within acceptable limits (96.23-105.71\% recovery); the percent recovery has to be in between $80-120 \% .^{11}$ The repeatability precision and the intermediate precision of both methods were less than 5\% RSD. The limit of detection and limit of quantitation were calculated by the residual standard deviation of a regression line and displayed as 0.27 and $0.81 \mu \mathrm{g} / \mathrm{spot}$ for TLC-densitometry, and 0.16 and $0.47 \mu \mathrm{g} /$ spot for TCL-image analysis, respectively. These values revealed satisfactory sensitivity of both methods. The robustness expressed the values of $0.97 \%$ RSD for TLC-densitometry and $0.51 \%$ RSD for TLC image analysis. This implied that the changes in the mobile phase ratio did not affect both methods. The results from method validation confirmed that TLC-densitometry and TLC-image analysis techniques were trustworthy and effective for the quantitative analysis of rotenone in D. elliptica stems.

Table 3: Method validity of thin-layer chromatography-densitometry and thin-layer chromatography image analysis of rotenone in $D$. elliptica stems.

\begin{tabular}{ccc}
\hline Validity Parameter & TLC-densitometry & TLC-image analysis \\
\hline Accuracy (\%Recovery) & $96.23-105.09$ & $96.57-105.71$ \\
Precision:Repeatabillity (\%RSD) & $1.67-2.19$ & $1.51-2.21$ \\
Precision:Intermediate precision (\%RSD) & $3.28-4.18$ & $3.43-4.16$ \\
Robustness $(\% \mathrm{RSD})$ & $0.97-4.33$ & $0.51-3.27$ \\
Limit of detection $(\mu \mathrm{g} / \mathrm{spot})$ & 0.13 & 0.27 \\
Limit of quantitation $(\mu \mathrm{g} / \mathrm{spot})$ & 0.81 & 0.83 \\
\hline
\end{tabular}

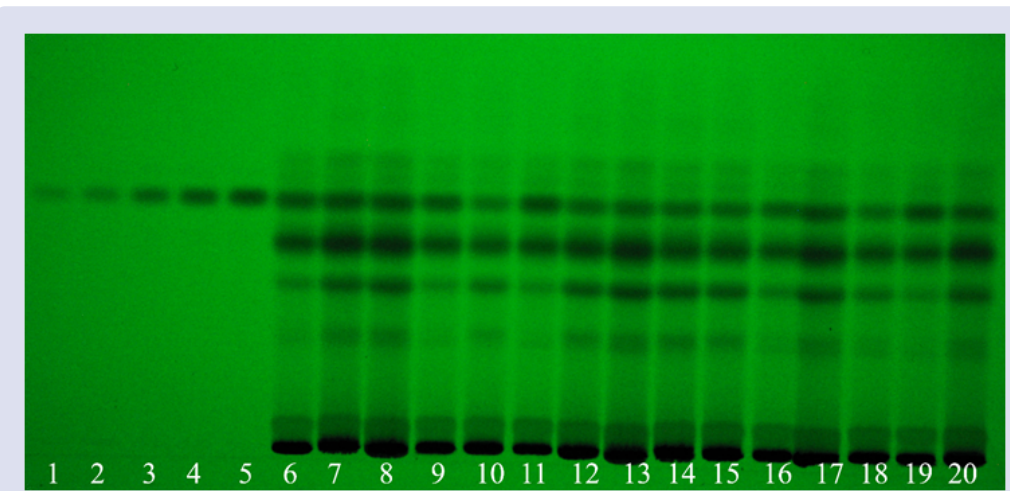

Figure 7: TLC chromatogram of rotenone in D. elliptica track 1-5 (rotenone) and track 6-20 (samples) at $254 \mathrm{~nm}$.

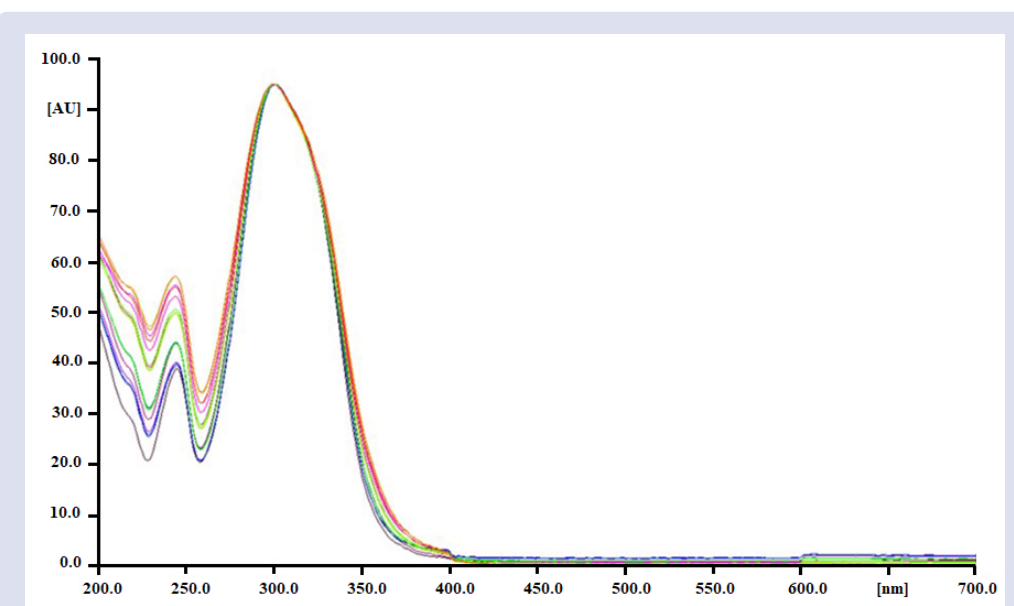

Figure 8: The absorption spectra of rotenone in standard and all sample bands. 


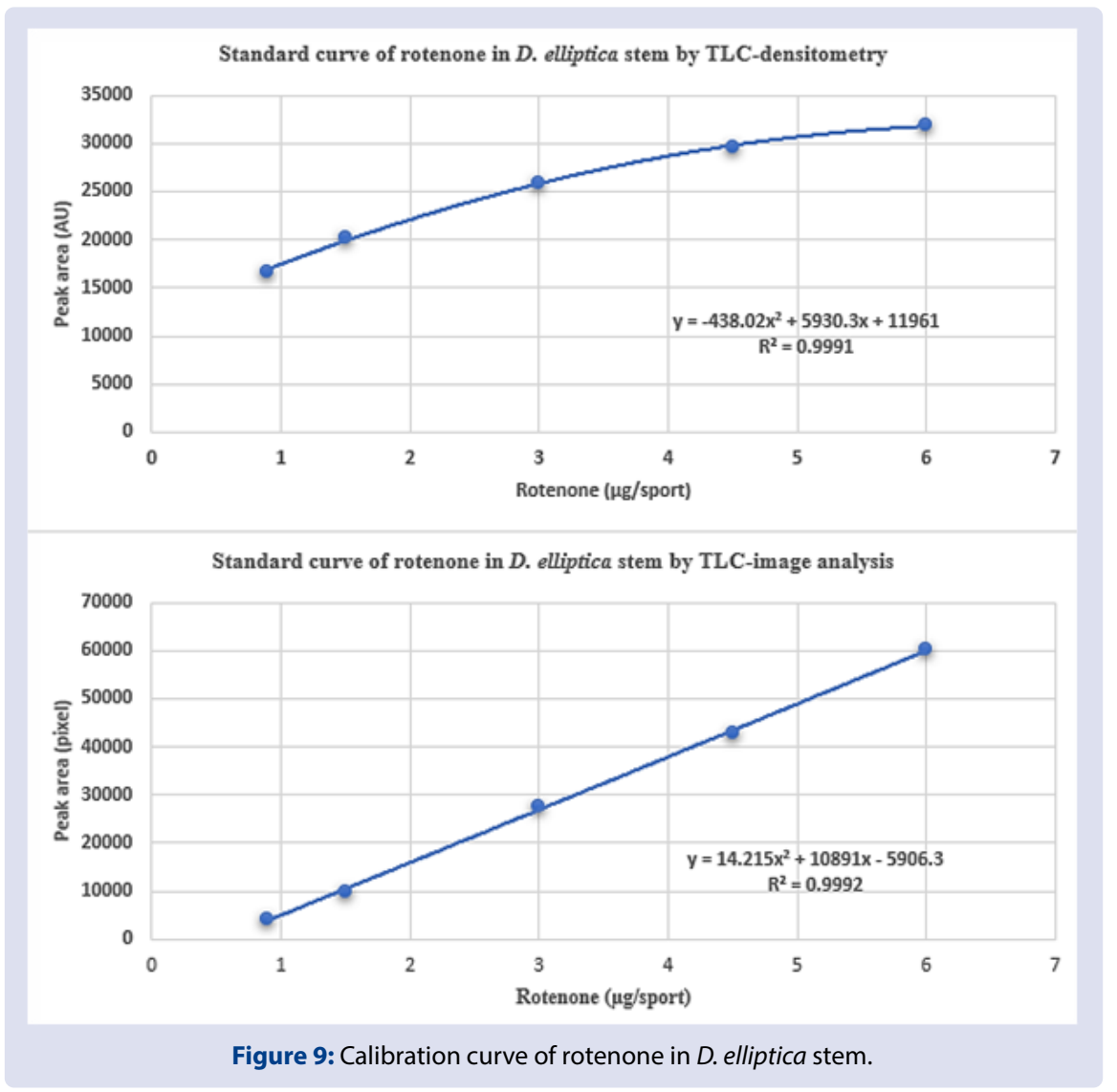

\section{CONCLUSION}

Pharmacognostic specification with reference to rotenone content of the D. elliptica stem was established for quality assessment of this crude drug. Developed TLC-densitometry and TLC-image analysis were valid for quantitative determination of rotenone in ethanolic extracts of $D$. elliptica stem. TLC-image analysis using a free analytical software, ImageJ could be used as an alternative method for rotenone quantification in D. elliptica stem as its simplicity and inexpensive instruments.

\section{CONFLICTS OF INTEREST}

The authors declare no conflicts of interest.

\section{ACKNOWLEDGMENTS}

The authors are supported by the scholarship from "The 90th Anniversary of Chulalongkorn University Fund (Ratchadaphiseksomphot Endowment Fund)," Graduate School, Chulalongkorn University. The authors wish to express gratitude to College of Public Health Sciences, Chulalongkorn University, and all the staff members for necessary assistance and instrumental support. Last but not least, K.P. would like to sincerely thank Mae Fah Luang University for giving him an opportunity to complete this research.

\section{REFERENCES}

1. Ujváry I. Chapter 3 - Pest Control Agents from Natural Products. In: Krieger R, editor. Hayes' Handbook of Pesticide Toxicology (Third Edition). New York: Academic Press; 2010. p. 119-229.

2. Gupta RC. CHAPTER 42 - Rotenone. In: Gupta RC, editor. Veterinary Toxicology. Oxford: Academic Press; 2007. p. 499-501.

3. Lawana V, Cannon JR. Rotenone neurotoxicity: Relevance to Parkinson's disease. In: Advances in Neurotoxicology: Academic Press; 2020.
4. Wang $Y$, Liu W, Yang J, Wang F, Sima Y, Zhong Z-m, et al. Parkinson's disease-like motor and non-motor symptoms in rotenone-treated zebrafish. NeuroToxicology. 2017;58:103-9.

5. Zeng X-S, Geng W-S, Jia J-J. Neurotoxin-Induced Animal Models of Parkinson Disease: Pathogenic Mechanism and Assessment. ASN Neuro. 2018;10:1759091418777438.

6. World Health Organization. Quality control methods for herbal materials. Geneva, Switzerland: WHO press; 2011.

7. European Medicines Agency. Reflection Paper on Markers Used for Quantitative and Qualitative Analysis of Herbal Medicinal Products and Traditional Herbal Medicinal Products. London: European Medicines Agency 2008 [cited 2018 November, 18]; Available from: https://www.ema.europa.eu/documents/ scientific-guideline/draft-reflection-paper-markers-used-quantitative-qualitativeanalysis-herbal-medicinal-products_en.pdf

8. Peng-ngummuang $K$, Palanuvej $C$, Ruangrungsi N. Pharmacognostic specification and coumarin content of Alyxia reinwardtii inner bark. Engineering Journal. 2015;19(3):15-20.

9. PitakpawasutthiY, Suwatronnakorn M, Issaravanich S, Palanuvej C, Ruangrungs N. Quality evaluation with reference to clitoriacetal and in vitro antioxidant activities of Clitoria macrophylla root. Journal of Advanced Pharmaceutical Technology \& Research. 2019;10(4):169-77.

10. The National Institutes of Health. ImageJ: Image Processing and Analysis in Java: The National Institutes of Health; 2018 [cited 14 April 2018]. Available from: https://imagej.nih.gov/ij/index.html.

11. Validation of analytical procedures: text and methodology Q2(R1). In Proceedings of the International Conference on Harmonisation of Technical Requirements for Registration of Pharmaceuticals for Human Use, April 25-27; 2005.

12. Mukherjee PK. Quality Control Herbal Drugs: An Approach to Evaluation of Botanicals. first edition ed. New Delhi, India: Business Horizons; 2007.

13. Sherma J, Fried B. Thin Layer Chromatographic Analysis of Biological Samples. A Review. Journal of Liquid Chromatography \& Related Technologies. 2005;28(15):2297-314.

14. Stroka J, Spangenberg B, Anklam E. NEW APPROACHES IN TLC DENSITOMETRY. Journal of Liquid Chromatography \& Related Technologies. 2002;25(10-11):1497-513. 


\section{GRAPHICAL ABSTRACT}

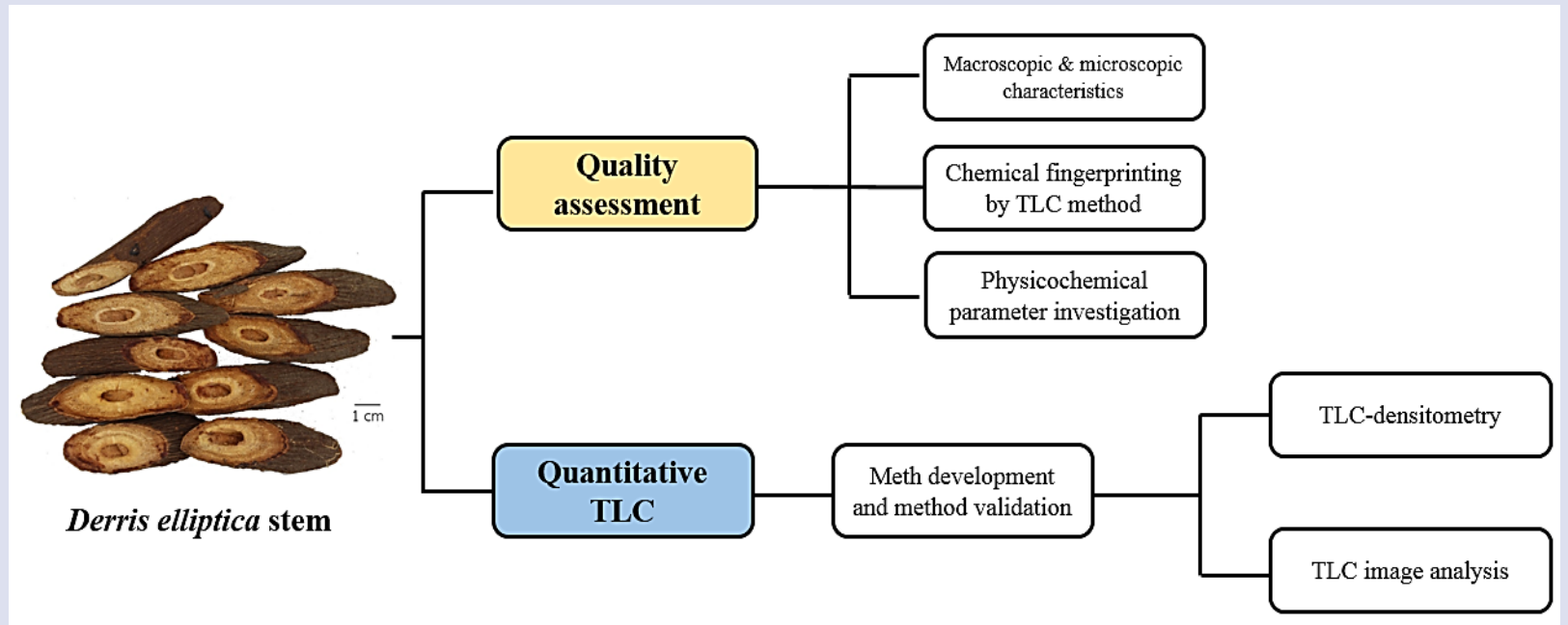

\section{SUMMARY}

- Derris elliptica (Wall.) Benth. (Leguminosae) is the tropical plant which has been used as natural poison as well as veterinary medicine due to its best-known phytochemical compound, rotenone to kill invertebrates and fish.

- This study provided macroscopical and microscopical characteristics as well as chemical fingerprinting which could be beneficial for correct identification, collection and investigation of the plant.

- In addition, the physicochemical parameters; loss on drying, water content, total ash, acid-insoluble ash, and extractive value, were evaluated for controlling the $D$. elliptica stems quality.

- The contents of rotenone in D. elliptica stem ethanolic extract evaluated by TLC-densitometry and TLC-image analysis were found to be $0.2870 \pm 0.1242$ and $0.2844 \pm 0.1209 \%$ by dried weight, respectively. The result between these two analytical methods were shown no significant difference.

\section{ABOUT AUTHORS}

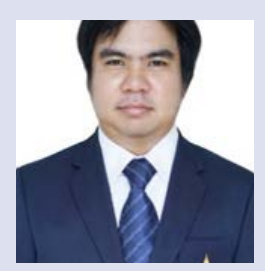

Krittapat Phairoh: He is currently studying Ph.D. at the College of Public Health Sciences, Chulalongkorn University. He graduated his bachelor degree in Applied Thai Traditional Medicine, Mae Fah Luang University. He has focused his researches on scientific evidence based - traditional Thai and alternative medicines. His researches involve herbal drug standardization, chemical qualitative/quantitative analyses and biological activity evaluation.

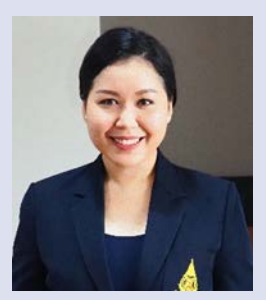

Parichart Hongsing: Dr. Parichart Hongsing is a lecturer and researcher at the Department of Applied Thai Traditional Medicine, Mae Fah Luang University. She has focused her research on scientific evidence based - traditional Thai and alternative medicines. Her career involves clinical research, herbal drug standardization, chemical qualitative/ quantitative analyses and biological activity evaluation.

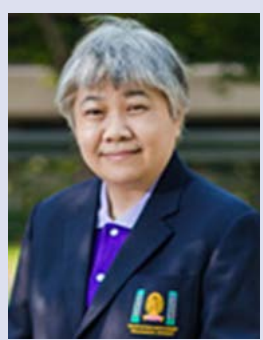

Chanida Palanuvej: She is an Associate Professor at the College of Public Health Sciences, Chulalongkorn University. She has focused her researches on scientific evidence based - traditional Thai and alternative medicines. Her career involves herbal drug standardization, chemical qualitative/ quantitative analyses and biological activity evaluation. She has collaborated with Department for Development of Thai Traditional and Alternative Medicine, Ministry of Public Health for establishing "Pharmacognostic Specification of Thai Crude Drugs" which have been printed as reference books in 2007 (Volume 1) and 2013 (Volume 2). 


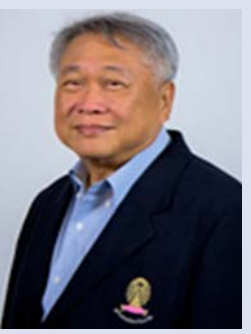

Nijsiri Ruangrungsi: $\mathrm{He}$ is an Associate Professor at the College of Public Health Sciences, Chulalongkorn University. He pursued the career of pharmacognosy curriculum as well as research on chemistry of natural products. He has got enormous experiences in plant taxonomy, phytochemistry and herbal medicine. He is an expert in medicinal plants and pharmacognosy of Ministry of Public Health. He is appointed to be a committee in the National Science and Technology Development Board of National Science and Technology Development Agency (NSTDA). He is also an advisory member of National Nanotechnology Center (Nano-cosmeceutics).

Cite this article: Phairoh K, Hongsing P, Palanuvej C, Ruangrungsi N. Pharmacognostic Specification and Rotenone Content in Derris elliptica Stems. Pharmacog J. 2021;13(1): 124-32 